Andreas Valentin

Patrick Ferdinande ESICM Working Group on Quality Improvement

\section{Recommendations on basic requirements for intensive care units: structural and organizational aspects}

Received: 7 February 2011

Accepted: 9 June 2011

Published online: 15 September 2011

(C) Copyright jointly held by Springer and ESICM 2011

This article is discussed in the editorial available at doi:10.1007/s00134-011-2332-z.

Electronic supplementary material

The online version of this article (doi:10.1007/s00134-011-2300-7) contains supplementary material, which is available to authorized users.

\section{A. Valentin ( $)$}

General and Medical ICU,

Rudolfstiftung Hospital, Juchgasse 25,

1030 Vienna, Austria

e-mail: andreas.valentin@meduniwien.ac.at

Tel.: +43-1-711652224

Fax: +43-1-711652229

\section{P. Ferdinande}

Surgical and Transplantation ICU,

University Hospital Gasthuisberg,

Leuven, Belgium
Abstract Objective: To provide guidance and recommendations for the planning or renovation of intensive care units (ICUs) with respect to the specific characteristics relevant to organizational and structural aspects of intensive care medicine.

Methodology: The Working Group on Quality Improvement (WGQI) of the European Society of Intensive Care Medicine (ESICM) identified the basic requirements for ICUs by a comprehensive literature search and an iterative process with several rounds of consensus finding with the participation of 47 intensive care physicians from 23 countries. The starting point of this process was an ESICM recommendation published in 1997 with the need for an updated version. Results: The document consists of operational guidelines and design recommendations for ICUs. In the first part it covers the definition and objectives of an ICU, functional criteria, activity criteria, and the management of equipment. The second part deals with recommendations with respect to the planning process, floorplan and connections, accommodation, fire safety, central services, and the necessary communication systems. Conclusion: This document provides a detailed framework for the planning or renovation of ICUs based on a multinational consensus within the ESICM.

Keywords Intensive care medicine . Organization - Structural requirements - Quality of care . Consensus paper

$\begin{array}{ll}\text { Abbreviations } \\ \text { AHCP } & \begin{array}{l}\text { Allied health care } \\ \text { professional } \\ \text { Decibel }\end{array} \\ \text { dB } & \begin{array}{l}\text { European Society of } \\ \text { ESICM }\end{array} \\ \text { ESM } & \begin{array}{l}\text { Intensive Care Medicine } \\ \text { Electronic supplementary } \\ \text { material }\end{array} \\ \text { FTE } & \text { Full time equivalent } \\ \text { HDU } & \text { High dependency unit } \\ \text { ICU } & \text { Intensive care unit } \\ \text { iv } & \text { Intravenous } \\ \text { LOC(s) } & \begin{array}{l}\text { Level(s) of care } \\ \text { Mand } F\end{array} \\ \text { WQI } & \begin{array}{l}\text { Working Group of Quality } \\ \text { Improvement (ESICM) }\end{array}\end{array}$

\section{Background}

In 1997 a task force of the European Society of Intensive Care Medicine (ESICM) published a paper aimed to describe minimum requirements for intensive care departments [1]. These recommendations had an impact in guidelines of national intensive care societies as well as legislative documents (e.g., in Greece). Since then intensive care medicine and even more the conditions of its practice have changed considerably causing the need 
for an update of these recommendations. In 2008 the ESICM Working Group of Quality Improvement (WGQI) addressed this task and was endorsed by the ESICM council and the ESICM executive committee.

\section{Methods}

The formal work on this project was started during a meeting of the WGQI in March 2009 (Brussels) and continued with meetings in October 2009 (Vienna), March 2010 (Brussels), and October 2010 (Barcelona). An advisory group with 47 participants from 23 countries was constituted (see Acknowledgements). A comprehensive literature search in Medline (starting with the year 1990) was performed and then complemented by references proposed by the members of the advisory group. An important limitation that was obvious from the beginning of the process was that evidence from the literature for this subject is scarce, and the document is therefore based on expert opinion in many places. In a first step of the process detailed and structured comments on the paper from 1997 were collected from the members of the advisory group and this built the basis for a first draft of the new document. The document in progress was circulated by e-mail three times in total and edited by all members of the advisory group at each stage. Remaining disagreements were discussed and resolved during the WGQI meetings stated above, where an agreement of at least $75 \%$ of the WGQI members present had to be reached. After a final round by e-mail, to check that the advisory group agreed on the final version, the document was ultimately approved by the WGQI on 12 October 2010 in Barcelona.

The document consists of operational guidelines and design recommendations for intensive care units. All parts with listings or detailed technical descriptions have been moved to the electronic supplementary material (ESM) and are available there.

\section{Recommendations-part I: operational guidelines}

Definition and objectives of an intensive care unit

The intensive care unit (ICU) is a distinct organizational and geographic entity for clinical activity and care, operating in cooperation with other departments integrated in a hospital. The ICU is preferably an independent unit or department that functions as a closed unit under the full medical responsibility of the ICU staff in close concert with the referring medical specialists [2, 3]. It has a defined geographical location concentrating the human and technical resources, such as manpower, professional skills and competencies, technical equipment, and the necessary space. The characteristics of medical, nursing, and allied health personnel staffing; technical equipment; architecture; and functioning should be clearly defined [4-6]. Interdisciplinary written arrangements about workflow, competencies, medical standards, regulations of cooperation, and mechanisms for decision-making are helpful to embed competencies and to standardize clinical workflow.

The objectives of an ICU are the monitoring and support of threatened or failing vital functions in critically ill patients who have illnesses with the potential to endanger life, in order to perform adequate diagnostic measures and medical or surgical therapies to improve outcome. The patient population may present with a large variety of pathologies but shares the potential reversibility of one or more threatened vital functions. Every ICU should provide the know-how and equipment based on the mission statement of the individual ICU to assure "stateof-the-art intensive care medicine."

Timely mobilization of the ICU team and its support services plays an important role in the efficient use of acute care facilities, for the coverage, triage, and outreach management of critically ill patients outside the ICU. Shared protocols between the ICU and other departments of the hospital (e.g., the emergency department) enhance throughput and decrease overall hospital mortality of critically ill patients [7].

These proposed guidelines are valid for ICUs caring for adult patients. Neonatal/pediatric ICUs may have to be adapted accordingly. Specific pediatric units are desirable if the turnover rate justifies such a unit and warrants expertise. Whenever possible pediatric patients should be treated in specialized pediatric ICUs [8].

\section{Functional criteria}

\section{Location}

An ICU will be situated in a hospital with appropriate departments to ensure that the multidisciplinary needs of intensive care medicine are met [9-11]. Surgical and medical diagnostic and therapeutic facilities must be represented, and medical, anesthesiological, surgical, and radiological consultants must be available for ICU purposes on a $24 \mathrm{~h} /$ day basis. Not all hospitals will develop their ICU facilities in the same way, with the same competencies and identical structures and equipment. ICUs must be adapted to the region and the hospital they serve in terms of size, staffing, and technology.

\section{Size}

An ICU should accommodate as a minimum at least 6 beds $[12,13]$, with $8-12$ beds considered as the optimum. 
Hospitals with several smaller units should be encouraged to rearrange these units into a single larger department to improve efficiency. On the other hand, a larger ICU may take the opportunity to create separate, specialized functional subunits with 6-8 beds, sharing the same geographical, administrative, and other facilities. Cohorting of patients in such subunits may be based on specific processes of care or pathology. The size of the unit is also influenced by the geographical and economic situation. A volume-effect in terms of sufficient numbers of admitted patients and numbers of therapeutic interventions is also recognized to maintain the quality of activities such as the provision of mechanical ventilation and renal replacement therapy [14-16].

\section{Medical staffing}

Director of the intensive care unit. The responsibility for the administrative and medical management of the unit is held by a physician, whose professional activities are devoted full-time or at least $75 \%$ of the time to intensive care, who holds the position of director of the ICU. The head of the ICU has the sole administrative and medical responsibility for this unit and cannot hold top-level responsibilities in other departments or facilities of the hospital. The head of the ICU should be a senior accredited specialist in intensive care medicine as defined at country level, usually with a prior degree in anesthesiology, internal medicine, or surgery and have had a formal education, training, and experience in intensive care medicine as described by the ESICM guidelines [17].

Medical staff members. The head of the ICU is assisted by physicians qualified in intensive care medicine. The number of staff required will be calculated according to the number of beds in the unit, number of shifts per day, desired occupancy rate, extra manpower for holidays and illness, number of days each professional is working per week, and the level of care and as a function of clinical, research, and teaching workload. Extended work shifts have been shown to negatively impact the safety of patients as well as medical staff [18-20]. The number of full time equivalent (FTE) physicians qualified in intensive care medicine per six to eight intensive care beds (at level of care II, see section "Activity Criteria") can be calculated (according to the European working hours directives) with the formula provided in paragraph 9 of the ESM [21]. An experienced physician certified in intensive care medicine is on duty and available upon request at short notice in the hospital during "off duty hours." The regular medical staff members of the ICU treat patients using state-of-the-art techniques and may consult specialists in different medical, surgical, or diagnostic disciplines whenever necessary.
The regular medical staff members have the task of coordinating the referring physician and consulting medical specialties. The staff members of the ICU take over the medical and administrative responsibilities of the care of the patients admitted to the unit. They define admission and discharge criteria and carry the responsibility for diagnostic and therapeutic protocols to standardize care in the ICU. An important task of the medical staff in training centers is to supervise and teach the doctors in training. For this purpose formal daily rounds are organized to give information and plan therapy. All ICU health professionals involved in direct patient care should participate in these rounds.

Medical trainees. Trainees in medical and surgical specialties (e.g., anesthesiology, internal medicine, pulmonology, surgery) may, after 2 years of training in their primary specialty and within the frame of their specialty, work in an ICU under clearly defined supervision. Depending on the legal framework operating in the individual country, these training periods should have a minimum duration of 6 months (optimally 1 year) for those planning to qualify in intensive care medicine and 3 months (optimally 6 months) for others. During these training periods, the trainees are involved full-time in the activities of the ICU.

Trainees assure supervised continuity and participate in the duties of the ICU under the supervision of a qualified intensive care physician. The regular staff carries final medical responsibility. Under ideal conditions, there should be an overlapping in the training periods to reinforce the expertise in the group of trainees.

Continuity of medical activity. The continuity of medical care in the ICU during nights, weekends, and holidays is assured by the regular medical staff of the ICU on a 24 h/day basis [22-24]. They can be assisted by skilled and experienced residents from other departments with basic training in intensive care medicine, provided there is a back-up of the regular staff around the clock [25-28]. This activity needs to be considered in the calculation of requested regular staff.

\section{Nursing staff}

Organization and responsibilities. Intensive care medicine is the result of close cooperation among doctors, nurses, and allied health care professionals (AHCP). An efficient process of communication has to be organized between the medical and nursing staff of the ICU. Tasks and responsibilities have to be clearly defined.

Head nurse. The nursing staff is managed by a dedicated, full-time head nurse, who is responsible for the functioning and quality of the nursing care. The head 
nurse should have extensive experience in intensive care nursing and should be supported by at least one deputy head nurse able to replace him (her). The head nurse should ensure the continuing education of the nursing staff. Head nurses and deputy head nurses should not normally be expected to participate in routine nursing activities. The head nurse works in collaboration with the medical director, and together they provide policies and protocols, and directives and support to the team.

Nurses. Intensive care nurses are registered nursing personnel, formally trained in intensive care medicine and emergency medicine. A specific program should be available to assure a minimum of competencies amongst the nursing staff $[29,30]$. An experienced nurse (head nurse or a dedicated nurse) is in charge of education and evaluation of the competencies of the nurses. In the near future, a specific curriculum for ICU nurses should be available. In addition to clinical expertise, some nurses may develop specific skills (e.g., human resource management, equipment, research, teaching new nurses) and assume the responsibility for this aspect of unit management.

Staff meetings together with physicians, nurses, and AHCP must be regularly organized in order to carry out the following:

- Discuss difficult cases and address ethical issues

- Present new equipment

- Discuss protocols

- Share information and discuss organization of the ICU

- Provide continuous education

The number of intensive care nurses necessary to provide appropriate care and observation is calculated according to the levels of care (LOCs) in the ICU [31-44]. For the description of the LOCs refer to the section "Activity criteria."

Nurses in training. Nurses in specialty training for intensive care and emergency nursing must be trained in ICUs under the supervision of sufficient training personnel. They should not be seen as substitute for regular intensive care nursing staff but may be gradually assigned to patient care according to their actual level of training.

\section{Allied health care personnel [45]}

Physiotherapists. One physiotherapist with dedicated training and expertise in critically ill patients should be available per five beds for level III care on a 7 day/week basis.

Technicians. Maintenance, calibration, and repair of technical equipment in the ICU must to be organized. This facility can be shared with other departments of the hospital but a 24-h availability has to be organized with priority for the ICU.
Radiology technician. Should be on call around the clock. Interpretation of the medical imaging by the radiologist must be available at all times.

Dietician. Should be on call during normal working hours.

Speech and language therapist. Should be available to consult during normal working hours.

Psychologist. Should be available to consult during normal working hours.

Occupational therapist. Should be available to consult during normal working hours.

Clinical pharmacist. Should be available to consult during normal working hours. A sufficient collaboration with pharmacy is of particular importance with respect to patient safety.

\section{Administrative personnel}

One medical secretary is required per 12 intensive care beds. Basic tasks are patient administration, external and internal communication exchange, and typing of reports and documents. One secretary per six beds may be desirable if she/he is also involved in arranging laboratory journals and medical files. Another approach is to calculate the number of medical secretarial assistants as one FTE per 500-700 admissions. Support for formal teaching activities may increase the need.

\section{Cleaning personnel}

A specialized group of cleaning personnel familiar with the ICU environment should be available for the ICU. They should be familiar with infection control, prevention protocols, and hazards of medical equipment. Cleaning and disinfection of the patient areas are performed under the nurse's supervision. A checklist of the cleaning status must be kept. Regular updates should be provided to ensure cleaning protocols reflect best practice.

\section{Activity criteria}

To assure optimal patient care, a complex and time-critical interplay among different groups of professionals, using a wide range of pharmacological interventions, treatments, and procedures, is needed. Accordingly, the workflow in the ICU is complex and dynamic, with many shared tasks and overlapping activities. Thus, well- 
structured collaboration among physicians, nurses, and all other professionals working in the ICU is essential.

This includes the following:

- Presence of inter-professional clinical rounds [46]

- Standardized and structured processes of handover and of interdisciplinary and interprofessional information transfer

- Use of a clinical information system (patient data management system)

Finally, although beyond the scope of these recommendations, it needs to be mentioned that a growing body of literature indicates that management and climate in the ICU can influence the satisfaction of patient relatives, the well-being of health care workers, and might even have an impact on patient outcomes [9-11, 47, 48].

\section{Definition of intensive care patients}

Two types of patients are likely to benefit from admission to an ICU [40, 49-51]:

1. Patients requiring monitoring and treatment because one or more vital functions are threatened by an acute (or an acute on chronic) disease (e.g., sepsis, myocardial infarction, gastrointestinal haemorrhage) or by the sequelae of surgical or other intensive treatment (e.g., percutaneous interventions) leading to life-threatening conditions.

2. Patients already having failure of one of the vital functions such as cardiovascular, respiratory, renal, metabolic, or cerebral function but with a reasonable chance of a meaningful functional recovery. In principle patients in known end-stages of untreatable terminal diseases are not admitted. Sometimes the need for palliative care requiring intensive care measures may be considered.

In addition, patients with brain death or in whom brain death is expected to occur and in whom organ donation is considered may be admitted.

\section{Definition of levels of care (LOCs)}

Three LOCs are proposed: III, II, and I.

Level of care III (highest). LOC III represents patients with multiple (two or more) acute vital organ failure of an immediate life-threatening character. These patients depend on pharmacological as well as device-related organ support such as hemodynamic support, respiratory assistance, or renal replacement therapy.
Level of care II. LOC II represents patients requiring monitoring and pharmacological and/or device-related support (e.g., hemodynamic support, respiratory assistance, renal replacement therapy) of only one acutely failing vital organ system with a life-threatening character.

Level of care I (lowest). LOC I patients experience signs of organ dysfunction necessitating continuous monitoring and minor pharmacological or device-related support. These patients are at risk of developing one or more acute organ failures. Included are patients recovering from one or more acute vital organ failures but whose condition is too unstable or when the nursing workload is too high/ complex to be managed on a regular ward.

For these different LOCs, the following minimum nurse/patient ratios are considered to be appropriate:

\begin{tabular}{lll}
\hline LOC & Nurse/patient ratio & Nursing FTE per ICU bed \\
\hline III & $1 / 1$ & 6 \\
II & $1 / 2$ & 3 \\
I & $1 / 3$ & 2 \\
\hline
\end{tabular}

The qualification of the nurses has to be taken in account. The nurse/patient ratio may be adapted according to the competencies of other allied health personnel

$L O C$ Level of care, FTE full time equivalent, ICU intensive care unit

Several LOCs can be integrated into the same ICU in a flexible organization model [52]. The nurse/patient ratios represent mean annual data and may need to be customized for each country [40, 49-51, 53]. The planned and operating nursing staff can be matched by using the Workload Utilization Ratio or similar instruments [54].

Hospital facilities may include a high dependency unit (HDU) that is characterized by the maximum provided LOC that does not exceed level I. The choice to organize a mixed ICU/HDU or rather to opt for two separate units (ICU and HDU) can be made bearing in mind the following considerations:

1. The bedside equipment has the least impact on ICU cost (in contrast to the salaries of personnel). In a mixed ICU/HDU all beds should be equipped to the highest level. Otherwise "internal" moves to adequately equipped beds will lead to problems described in point 2.

2. Moving patients between separate units or internally to adequately equipped beds carries certain risks including loss of information, hampers continuity in management, and creates an avoidable and unnecessary workload [55]. 
3. A mixed ICU/HDU unit necessitates additional creativity to use the available manpower as efficiently as possible. On days with concentrated high activity some fully equipped beds may remain empty. Capacity calculation should then be performed based on available manpower and workload rather than on number of equipped beds.

\section{Required number of intensive care beds}

The number of intensive care beds has to be calculated as a function of the type of the hospital, admission of specific disease categories, the geographic location of the hospital, number of acute beds, etc. A survey of the international literature shows figures in Europe of an average of $5 \%$ of hospital beds up to $10 \%$ in university hospitals. In the United States, the numbers are higher, but the cost-benefit of these ratios remains controversial. These numbers are indicative and depend also on the referral function of a hospital [12, 53, 56, 57].

Standards for architecture, medical and surgical staff and others have to be calculated for a $100 \%$ activity and occupancy rate. In practice, only $75 \%$ of the beds will be occupied if the occupancy rate is calculated on an hourly basis. This will allow the unit to cope with major emergencies and to avoid premature discharges.

\section{Quality control}

Quality control encompasses a wide variety of activities and items needed to objectivate and explain the excellence of performance, and benchmark with peers. A list of respective criteria is provided in paragraph 2 of the ESM.

Each ICU should evaluate its activity, bearing in mind that a critical minimum amount for each disease category is necessary to maintain medical and nursing expertise at adequate levels [14-16, 22, 23]. In this process of selfevaluation, choices may have to be made regarding transfer of patients to regional/national centers of excellence experienced in a specific domain of intensive care medicine or for specific critical care disease categories.

Every ICU is required to have a quality assessment and improvement program in order to compare with a national/European benchmark. This should include a report of complications and adverse events, and a system in which indicators that reflect quality and safety of care are continuously monitored.

These indicators should cover the process of care (i.e., mechanical ventilation, sedation, medication, IV lines, management, or complications), outcome (i.e., risk-adjusted mortality), and structure (i.e., staffing adequacy, protocol availability, medication errors protocol) $[58,59]$.
Morbidity and mortality conferences are strongly recommended. It is beyond the scope of present recommendations to go into detail to determine which quality indicators are best suited for these purposes [60-62].

The participation in regional, national, or international data collection and comparison systems should be encouraged, in order to maximize the safety and quality culture of the ICU.

\section{Management of equipment}

\section{Consumables}

Disposable material raises problems of storage and distribution because of its volume and turnover. A policy of frequent review of disposable material is absolutely fundamental for economic and quality purposes. A feature of intensive care medicine is that a very large number and variety of specific items must be kept within the unit. A small part can be stored at the bedside; the majority will be stored in the storage room. A simple system of stock control must be operated.

\section{Durable equipment}

Criteria for the selection, purchasing, storage, servicing, sterilization, and replacement of durable equipment are provided in paragraph 3 of the ESM.

\section{Recommendations-part II: design}

The purpose of this chapter is to formulate architectural standards for ICUs functioning at the highest level of intensive care medicine (LOC III). To assure a maximum flexibility in responding to the fluctuation of needed levels of care it is recommended to design an ICU with the provision for the highest level of care in all beds. There may be legal requirements for the design of ICUs operating in individual countries.

\section{Planning team}

The planning phase of a new ICU must be organized by a multidisciplinary team including, at least, the director of the future ICU, a representative of the medical staff, the head nurse, the architect, a representative of the hospital management, and an engineer. This planning team should be advised by a safety officer, the hospital infection control specialist, and representatives of referring medical and surgical departments in the hospital. The participation 
of a representative of a patients' association should be considered.

\section{Floor plan and connections}

The unit consists of a geographically distinct entity in the hospital with controlled access. The through-traffic of patients and provisioning not intended for the ICU should be avoided. Public and visitor traffic to the ICU should be separated from professional and supply traffic. Whenever possible horizontal connections with the operating theaters and emergency department are recommended and a centrally located keyed oversized elevator for patient transport with priority for the ICU assures the connection with referring and diagnostic departments. The total area of the ICU is estimated to be roughly $2.5-3$ times the total area devoted to patient care.

Layout of the ICU should allow rapid access from the following:

- The emergency department

- The operating theaters and postoperative areas

- The medical imaging department

- The functional testing facilities (e.g., catheter lab, endoscopy)

Fast and easy connections have to be established with the following:

- Blood transfusion service

- Pharmacy and pharmacology services

- Technical support services

- Laboratory and microbiology service

- Physiotherapy service

Lines of communication must be available on a roundthe-clock basis.

\section{Accommodation}

\section{Patient area}

The area for patient care is a minimum of $25 \mathrm{~m}^{2}$ for single rooms and $20 \mathrm{~m}^{2}$ per bed for common rooms. The basic ground plan for single and common rooms is rectangular with at least $2.5-\mathrm{m}$ traffic area beyond the bed area. The doorways are wide enough and adequately positioned to allow a bed (with orthopedic traction, equipment for extracorporal membrane oxygenation, cot sides, etc.) to pass easily. In the construction specifications, the possible use of heavy equipment (mobile isotope cameras, mobile $\mathrm{X}$-ray equipment, air beds, etc.) has to be anticipated. The layout has to be adapted in a way that conscious patients are not distressed by the acute problems (arrhythmia, alarm, cardioversion, resuscitation) of other patients. Due respect for the privacy of the patient must be assured.

Single rooms are strongly recommended to minimize cross contamination and minimize patient stress because of unrelated illness, noise, and activities, to improve patients long-term outcomes [63]. In common rooms strong precautions to avoid cross infection are essential. Some single rooms should be equipped as isolation rooms (refer to special needs during outbreaks of the severe acute respiratory syndrome or flu epidemics) with additional technical characteristics (i.e., negative pressure rooms). The ratio of isolation rooms to the total number of ICU beds should be in the range of $1-2$ per 10 beds but may be higher (5-6:10) in special ICUs (burn units, transplantation departments, infection units, etc.). Isolation rooms are equipped with an anteroom of at least $3 \mathrm{~m}^{2}$ for hand washing, gowning, and storage of isolation material. Appropriate instructions for isolation are visibly displayed at the entrance of each isolation room. A separate circuit for evacuation of contaminated material is recommended.

Visual observation of the patient. The patient should be able to be visualized at all times to facilitate detection of status changes and enhance implementation of therapeutic actions. This can be arranged from the central nursing station, but preferably by the patient's own nurse. Patients should be oriented so that they can see the nurse but cannot see the other patients. The constant visual contact between nurse and patient may be achieved by large window openings, glass doors etc. All patient rooms should possess a daylight source. The position of the patient's bed should ideally also allow a direct view out of the external window. Outer windows can only be opened with a safety lock.

Management functions in the patient area. The following management functions are accommodated in the patient area [64-66]. Central power sources, medical gases, water, and plumbing are described in the section "Central services."

1. Communication.

- One telephone for outgoing calls and in-hospital communication unless a wireless phone system is in place in every room.

- An intercom between patient rooms and nursing station.

- A manually triggered alarm system allowing immediate notification of the medical staff.

- Large wall clock and calendar.

- Multimedia access to internet, alternative nonverbal communication tools. 
2. Administrative equipment: Individual workstations per bed for patient files, monitoring, charts, imaging, lab reports are recommended. A paper backup solution in case of breakdown must be provided. As an alternative a counter with flow sheet charting surface and shelves for patient files, charts, X-rays, and lab forms must be provided per patient area.

3. X-ray film viewer or a screen for viewing digital images.

4. Storage: A lockable cupboard with drawers and shelves for storage of small amounts of disposable material, drugs, wound dressings, sampling equipment, material for intubation, and emergency drugs is provided. This function may be also accomplished by a trolley. Uniformity in arrangement of these materials is mandatory for provisioning and easy identification in emergency situations.

5. Separate pass-through cupboards for clean and contaminated material.

6. Monitoring equipment (see below and paragraph 4 of the ESM).

Services in patient areas. Access to the patient is a top priority for intensive care. All sockets and service outlets should be distributed on both sides of the bed and arranged in a way that there is minimal interference with nursing care. Adequate access to the head of the bed should also be provided for endotracheal intubation, resuscitation, and central venous catheterization. Two options can be taken: first, a layout with the bedhead against the wall, which has the disadvantage of limited access to the head of the patient in emergency situations; second, the freestanding arrangement where the services are brought down from the ceiling on a stalactite structure. Although the second solution is more expensive, it is to be recommended for optimal access to the head of the patient. The outlets are mounted between 120 and $180 \mathrm{~cm}$ from the floor. Services in the patient area must obviously include appropriate supply with electricity, vacuum, oxygen, compressed air, and water. Electronic equipment includes monitoring and computer systems. A more detailed description is given in paragraph 4 of the ESM.

\section{Central nursing station}

The primary function of the central nursing station is an administrative one and in no way replaces the bedside activity of the nurse.

It contains the following:

- Shelves for forms, library

- Satellite pharmacy with central lockable drawer for narcotics

- Computer terminal(s)

- Telephone, intercom, and emergency call systems
- Satellite storage room for sterile and nonsterile clean material

- Optional visual display with access to individual patient monitoring with alarm recording

- Drug preparation area

The central station is equipped with air-conditioning, adequate overhead lighting, a wall-mounted clock, handbasin, and writing and preparation counters.

\section{Storage}

Sufficient storage place outside the patient area is essential. The storage room should be easily accessible for nursing and medical staff, at a distance of a maximum of $30 \mathrm{~m}$ from the patient area, ideally with an approach both from the patient area and from the supply route. Storage room for consumables and durable equipment should be calculated with at least $10 \mathrm{~m}^{2} / \mathrm{bed}$. Details are described in paragraph 5 of the ESM.

\section{Utility}

Two completely separate spaces for clean $\left(15 \mathrm{~m}^{2}\right)$ and dirty $\left(25 \mathrm{~m}^{2}\right)$ utility rooms with separate access are necessary. The clean utility room is used for the storage of linen and assembling of sterile material. One dirty utility room is used for the removal of soiled linen, waste, etc. It contains a clinical sink and hopper. A second dirty utility room for dismantling used equipment is desirable. The load on the dirty utility room will be reduced if individual patient rooms are equipped with bedpan-cleaning equipment.

The utility rooms are air-conditioned. All air supplied to the dirty utility room is extracted. Removal of soiled items and waste should occur through a separate corridor.

\section{Nurse's office}

At least $15 \mathrm{~m}^{2}$ is provided as office space for the head nurse with separate telephone extension, intercom, notice boards, and alarm system for bedside calls.

\section{Medical office}

At least $20 \mathrm{~m}^{2}$ is provided as office space per physician with full-time activity in the ICU. It is equipped with telephone, intercom, and alarm registration in the ICU. A computer terminal with access to patient monitoring systems, laboratory, and diagnostic departments is essential. 


\section{Secretariat}

For every eight intensive care beds, $20 \mathrm{~m}^{2}$ is provided.

\section{Staff lounge}

A staff lounge of $40 \mathrm{~m}^{2}$ for eight intensive care beds includes the following:

- Staff restroom with beverage bars, emergency code alarm system, intercom terminal, and telephone extension

- Staff changing room, with lockable lockers, showers, and toilets (M and F).

\section{Physician-on-call bedroom(s)}

A $15 \mathrm{~m}^{2}$ room with bed, hand-basin, shower, toilet, telephone, intercom terminal, alarm code system, and television is provided. Access to daylight with operable window. Must be quiet.

\section{Laboratory}

A $15 \mathrm{~m}^{2}$ space is provided for laboratory (point of care testing) purposes allowing emergency analyses (blood gases, hemoglobin, hematocrit, glucose, lactate, serum electrolytes, etc.). Adequate bench space is available with at least 12 electrical points, sink, centrifuge, specimen refrigerator, intercom terminal, and telephone.

The central hospital laboratory can serve as an alternative provided that the service and the communication lines are extremely quick.

\section{Workshop}

A $28 \mathrm{~m}^{2}$ space is reserved as technical workshop. Bench, shelves, sink, six electrical outlets, oxygen, vacuum, and compressed air are provided. This is used for minor repairs, adjustment, and assembly and testing of equipment.

\section{Kitchen}

A $25 \mathrm{~m}^{2}$ kitchen for preparation of patients' special food and staff snacks that includes microwave, refrigerator, sink, cooker, and dishwasher is available. A separate kitchen in a relaxing environment for staff members is desirable.

\section{Reception area and relatives' rooms}

For relatives, $10 \mathrm{~m}^{2}$ per eight beds (1.5-2 chairs/bed) as well as $2 \times 10 \mathrm{~m}^{2}$ per eight beds (bed + shower) as sleep or rest cubicles are desirable. Intercom terminal, telephone, radio, toilet, sink, TV-plug, and public telephone are provided. It is desirable to have separate entrances to the unit for visitors and health care professionals.

\section{Receptionists' office}

A $10 \mathrm{~m}^{2}$ area adjacent to the reception area for units of more than 12 beds is reserved. Intercom terminal, telephone, and computer terminal are provided. The receptionists' office should be strategically located so that visitors must pass by the reception area for identification and for notification of the nursing staff.

\section{Special procedures/therapy room/admission room}

May be optionally important for specific units (burns, pacemaker implantation, emergency admissions). All bedside facilities are needed to continue monitoring and therapy of the patient. High intensity lighting and scrubup sink are needed. Needs are to be adapted for specific goals (radiography, angiography) with a size of at least $35 \mathrm{~m}^{2}$. When the ICU staff is also in charge of technical acts such as catheter insertions in non-ICU patients this special procedure room may be very useful.

\section{Seminar room-conference room}

A $40 \mathrm{~m}^{2}$ space for formal teaching, continuing education, and discussion with other medical disciplines is equipped with seating, projection facilities, wall board, video equipment, and air-conditioning. The area must be adapted to the size of the ICU. Sufficient individual working stations must be provided in order to facilitate workflow.

\section{Cleaners' room}

A 3-4 $\mathrm{m}^{2}$ space per eight beds is reserved for storage of cleaning equipment and material. Housekeeping material should not be used interchangeably with the public areas because of the possibilities of cross-contamination.

\section{Interview room}

A $15 \mathrm{~m}^{2}$ room is needed for interviews with patients' relatives.

\section{Corridors}

Transport of patients to and from the ICU should ideally be separated from public corridors and visitor waiting 
areas to assure patient privacy and rapid and unobstructed patient transport. The corridors are wide enough $(2.5 \mathrm{~m})$ and high enough to allow unobstructed transport of patients and possible support equipment (intra-aortic balloon, artificial heart, transport, ventilator). Oversized keyed elevators are necessary.

\section{Floor coverings}

Seamless floor covering should be chemically inert, resistant to antiseptics, and sound absorbing. Sound should be lower than $40 \mathrm{~dB}$ during daytime and $30 \mathrm{~dB}$ during nighttime. Special care is taken to avoid level differences. The floor coverings allow heavy-wheeled equipment to be moved without difficulty.

\section{Wall decoration and ceiling}

Easy to clean materials should be used that are nonabsorbent with low sound transmission. Neutral restful colors are recommended.

\section{Fire safety}

Fires affecting ICUs are rare. Still it is essential to make plans to prevent and to deal with fire. Each staff member must be familiar with the emergency plan, and annual rehearsals are strongly recommended. Critically ill patients are extremely vulnerable not only to fire but also to interruption of the life-supporting devices. The basic principles of fire safety are avoidance of fire, limitation of fire, safeguard of life, and reduction of material damage. (Each country has recommendations for hospital safety).

\section{Floor plan}

A floor plan should be displayed in a highly visible place. The contents of this plan are described in paragraph 6 of the ESM.

\section{Smoke and toxic gases}

Control of the development of smoke and toxic gases may be achieved by containment (fire-resisting walls, ceilings, floors, doors), dispersal (natural of mechanical ventilation), and pressurization of the patient areas (preventing entry of smoke). Compartmentalization and local fire control deserve attention in the early stages of disaster. Safety in the individual patient area is of utmost importance.

\section{Means of escape}

An alternative route of escape and an adjoining safe space to relocate the patient should be provided. This space, equipped with facilities of oxygen administration, compressed air and electricity, should be preferentially on the same level of the building and protected from wind and rain. Both postoperative areas and the emergency department may be used for this purpose.

\section{Related issues}

Fire doors may be a hindrance to normal traffic and continuous visual inspection if maintained in a closed position. Automatic electromagnetic or electromechanical devices can be used to hold them open. Electrical wiring and piped gases must run in separate conduits. Service ducts containing piped gases must be suitably ventilated. Gas pipes must be tested for leakage before use.

\section{Central services}

Control switches, shut-off valves, and monitoring (of pressure in gas pipes) must be located adjacent to the unit where they can be operated by the staff in emergency cases. They must be clearly marked to indicate the type of service or part of the hospital supplied. Interruption of central services at intermediate points between the source and the unit should be impossible. All compressed medical gases should at all times be supplied at the same pressure to prevent cross leakage in gas mixers. Central services include electricity, vacuum, oxygen, compressed air, other medical gases, ventilation, water supply and plumbing, heating, and lighting. A detailed description is provided in paragraph 7 of the ESM.

\section{Communication}

Provision should be made for easy and rapid communication within the unit and hospital systems that causes minimal audible distress to patients and staff. More detailed requirements with respect to telephone and internet connection, intercom, alarm calls, local communications, nurse and AHCP call system, and a personal on-call system are given in paragraph 8 of the ESM.

Acknowledgments We thank the participants of the advisory group listed below for their invaluable work and support. Advisory group: Apostolos Armaganidis (Greece), Antonio Artigas (Spain), Simon V. Baudouin (UK), Geoff Bellingan (UK), Willehad Boemke (Germany), Jan Braun (Germany), Edoardo Calderini (Italy), Maurizia Capuzzo (Italy), Vladimir Cerny (Czech Republik), Akos Csomos (Hungary), Maria Deja (Germany), Ruth Endacott (UK), Kurt Espersen (Denmark), Patrick Ferdinande 
(Belgium), Armand R.J. Girbes (Netherlands), Bertrand Guidet (France), Kevin Gunning (UK), Anne B. Guttormsen (Norway), Moshe Hersch (Israel), Ken Hillman (Australia), Gaetano Iapichino (Italy), Michael Joannidis (Austria), Max Jonas (UK), Andrew Jones (UK), Nina Maguina (Greece), Paulo Maia (Portugal), Claude Martin (France), Paolo Merlani (Switzerland), Adam Mikstacki (Poland), Rui Moreno (Portugal), Pedro NavarreteNavarro (Spain), Georg Ntoumenopoulos (UK), Roman Parežnik
(Slovenia), Michael Pinsky (USA), Alessandro Protti (Italy), Christian Putensen (Germany), Michael Quintel (Germany), Radovan Radonic (Croatia), Andrew Rhodes (UK), Hans Ulrich Rothen (Switzerland), Esko Ruokonen (Finland), Michael Sander (Germany), Claudia Spiess (Germany), Dierk Vagts (Germany), Andreas Valentin (Austria), Dominique Vandijck (Belgium), Débora Feijó Vieira (Brasil). We thank Andrew Rhodes for editorial advice.

\section{References}

1. Ferdinande P (1997) Recommendations on minimal requirements for intensive care departments. Members of the Task Force of the European Society of Intensive Care Medicine. Intensive Care Med 23:226-232

2. Brilli RJ, Spevetz A, Branson RD, Campbell GM, Cohen H, Dasta JF, Harvey MA, Kelley MA, Kelly KM, Rudis MI, St Andre AC, Stone JR, Teres D, Weled BJ (2001) Critical care delivery in the intensive care unit: defining clinical roles and the best practice model. Crit Care Med 29:2007-2019

3. Multz AS, Chalfin DB, Samson IM, Dantzker DR, Fein AM, Steinberg HN, Niederman MS, Scharf SM (1998) A "closed" medical intensive care unit (MICU) improves resource utilization when compared with an "open" MICU. Am J Respir Crit Care Med 157:1468-1473

4. [No authors listed] (1995) Guidelines for intensive care unit design. Guidelines/Practice Parameters Committee of the American College of Critical Care Medicine, Society of Critical Care Medicine. Crit Care Med 23:582-588

5. College of Intensive Care Medicine of Australia and New Zealand (2010) Minimum standards for intensive care units. http://www.cicm.org.au

6. Hasin Y, Danchin N, Filippatos GS, Heras M, Janssens U, Leor J, Nahir M, Parkhomenko A, Thygesen K, Tubaro M, Wallentin LC, Zakke I (2005) Recommendations for the structure, organization, and operation of intensive cardiac care units. Eur Heart J 26:1676-1682

7. Ferrer R, Artigas A, Levy MM, Blanco $\mathrm{J}$, Gonzalez-Diaz G, Garnacho-Montero J, Ibanez J, Palencia E, Quintana M, De la Torre-Prados MV (2008) Improvement in process of care and outcome after a multicenter severe sepsis educational program in Spain. JAMA 299:2294-2303
8. Ramnarayan P, Thiru K, Parslow RC, Harrison DA, Draper ES, Rowan KM (2010) Effect of specialist retrieval teams on outcomes in children admitted to paediatric intensive care units in England and Wales: a retrospective cohort study. Lancet 376:698-704

9. Minvielle E, Dervaux B, Retbi A, Aegerter P, Boumendil A, JarsGuincestre MC, Tenaillon A, Guidet B (2005) Culture, organization, and management in intensive care: construction and validation of a multidimensional questionnaire. J Crit Care 20:126-138

10. Minvielle E, Aegerter P, Dervaux B, Boumendil A, Retbi A, Jars-Guincestre MC, Guidet B (2008) Assessing organizational performance in intensive care units: a French experience. J Crit Care 23:236-244

11. Shortell SM, Rousseau DM, Gillies RR, Devers KJ, Simons TL (1991) Organizational assessment in intensive care units (ICUs): construct development, reliability, and validity of the ICU nurse-physician questionnaire. Med Care 29:709-726

12. Bertolini G, Rossi C, Brazzi L, Radrizzani D, Rossi G, Arrighi E, Simini B (2003) The relationship between labour cost per patient and the size of intensive care units: a multicentre prospective study. Intensive Care Med 29:2307-2311

13. Jacobs R, Dawson D (2003) Hospital efficiency targets. Health Econ 12:669-684

14. Kahn JM, Goss CH, Heagerty PJ, Kramer AA, O'Brien CR, Rubenfeld GD (2006) Hospital volume and the outcomes of mechanical ventilation. N Engl J Med 355:41-50

15. Lecuyer L, Chevret S, Guidet B, Aegerter P, Martel P, Schlemmer B, Azoulay E (2008) Case volume and mortality in haematological patients with acute respiratory failure. Eur Respir J 32:748-754
16. Pronovost PJ, Jenckes MW, Dorman T, Garrett E, Breslow MJ, Rosenfeld BA, Lipsett PA, Bass E (1999) Organizational characteristics of intensive care units related to outcomes of abdominal aortic surgery. JAMA 281:1310-1317

17. [No authors listed] (1994) Guidelines for training in intensive care medicine. European Society of Intensive Care Medicine. Intensive Care Med 20:80-81

18. Landrigan CP, Rothschild JM, Cronin JW, Kaushal R, Burdick E, Katz JT, Lilly CM, Stone PH, Lockley SW, Bates DW, Czeisler CA (2004) Effect of reducing interns' work hours on serious medical errors in intensive care units. N Engl J Med 351:1838-1848

19. Arnedt JT, Owens J, Crouch M, Stahl J, Carskadon MA (2005) Neurobehavioral performance of residents after heavy night call vs after alcohol ingestion. JAMA 294:1025-1033

20. Barger LK, Cade BE, Ayas NT, Cronin JW, Rosner B, Speizer FE, Czeisler CA (2005) Extended work shifts and the risk of motor vehicle crashes among interns. N Engl J Med 352:125-134

21. Vagts D (2007) Ärztliche Personalbedarfsermittlung in der Intensivmedizin. Anasthesiol Intensivmed Notfallmed Schmerzther 4:306-311

22. Dimick JB, Pronovost PJ, Heitmiller RF, Lipsett PA (2001) Intensive care unit physician staffing is associated with decreased length of stay, hospital cost, and complications after esophageal resection. Crit Care Med 29:753-758

23. Pronovost PJ, Angus DC, Dorman T, Robinson KA, Dremsizov TT, Young TL (2002) Physician staffing patterns and clinical outcomes in critically ill patients: a systematic review. JAMA 288:2151-2162

24. Burchardi H, Moerer O (2001) Twentyfour hour presence of physicians in the ICU. Crit Care 5:131-137 
25. Morales IJ, Peters SG, Afessa B (2003) Hospital mortality rate and length of stay in patients admitted at night to the intensive care unit. Crit Care Med 31:858-863

26. Finkielman JD, Morales J, Peters SG, Keegan MT, Ensminger SA, Lymp JF, Afessa B (2004) Mortality rate and length of stay of patients admitted to the intensive care unit in July. Crit Care Med 32:1161-1165

27. Barry WA, Rosenthal GE (2003) Is there a July phenomenon? The effect of July admission on intensive care mortality and length of stay in teaching hospitals. J Gen Intern Med 18:639-645

28. Luyt CE, Combes A, Aegerter P, Guidet B, Trouillet JL, Gibert C, Chastre J (2007) Mortality among patients admitted to intensive care units during weekday day shifts compared with "off" hours. Crit Care Med 35:3-11

29. Schmalenberg C, Kramer M (2007) Types of intensive care units with the healthiest, most productive work environments. Am J Crit Care 16:458-468 quiz 469

30. Gurses AP, Carayon P (2007) Performance obstacles of intensive care nurses. Nurs Res 56:185-194

31. Haupt MT, Bekes CE, Brilli RJ, Carl LC, Gray AW, Jastremski MS, Naylor DF, Pharm DM, Md AS, Wedel SK, Md MH (2003) Guidelines on critical care services and personnel:

recommendations based on a system of categorization of three levels of care. Crit Care Med 31:2677-2683

32. Goldhill D (2002) Levels of critical care for adult patients. Standards and guidelines. Intensive Care Society, London

33. Tarnow-Mordi WO, Hau C, Warden A, Shearer AJ (2000) Hospital mortality in relation to staff workload: a 4-year study in an adult intensive-care unit. Lancet 356:185-189

34. Pronovost PJ, Dang D, Dorman T, Lipsett PA, Garrett E, Jenckes M, Bass EB (2001) Intensive care unit nurse staffing and the risk for complications after abdominal aortic surgery. Eff Clin Pract 4:199-206

35. Dang D, Johantgen ME, Pronovost PJ, Jenckes MW, Bass EB (2002) Postoperative complications: does intensive care unit staff nursing make a difference? Heart Lung 31:219-228

36. Amaravadi RK, Dimick JB, Pronovost PJ, Lipsett PA (2000) ICU nurse-topatient ratio is associated with complications and resource use after esophagectomy. Intensive Care Med 26:1857-1862
37. Reis Miranda D, Moreno R, Iapichino G (1997) Nine equivalents of nursing manpower use score (NEMS). Intensive Care Med 23:760-765

38. Iapichino G, Radrizzani D, Bertolini G, Ferla L, Pasetti G, Pezzi A, Porta F, Miranda DR (2001) Daily classification of the level of care. A method to describe clinical course of illness, use of resources and quality of intensive care assistance. Intensive Care Med 27:131-136

39. Cullen DJ, Civetta JM, Briggs BA, Ferrara LC (1974) Therapeutic intervention scoring system: a method for quantitative comparison of patient care. Crit Care Med 2:57-60

40. Miranda DR, de Rijk A, Schaufeli W (1996) Simplified Therapeutic Intervention Scoring System: the TISS28 items-results from a multicenter study. Crit Care Med 24:64-73

41. [No authors listed] (1991) Time oriented score system (TOSS): a method for direct and quantitative assessment of nursing workload for ICU patients. Italian Multicenter Group of ICU research (GIRTI). Intensive Care Med 17:340-345

42. Miranda DR, Nap R, de Rijk A, Schaufeli W, Iapichino G (2003) Nursing activities score. Crit Care Med 31:374-382

43. Iapichino G, Radrizzani D, Ferla L, Pezzi A, Porta F, Zanforlin G, Miranda DR (2002) Description of trends in the course of illness of critically ill patients Markers of intensive care organization and performance. Intensive Care Med 28:985-989

44. Iapichino G, Radrizzani D, Pezzi A, Assi E, Di Mauro P, Mistraletti G, Porta F (2005) Evaluating daily nursing use and needs in the intensive care unit: a method to assess the rate and appropriateness of ICU resource use. Health Policy 73:228-234

45. National AHP and HCS Critical Care Advisory Group (UK) (2003) Allied Health Professionals (AHP) and Healthcare Scientists (HCS) critical care staffing guidance. A guideline for AHP and HCS Staffing levels. http://www.ukcpa.org/ukcpadocuments/ 2.pdf

46. Rothen HU, Stricker K, Einfalt J, Bauer P, Metnitz PG, Moreno RP, Takala J (2007) Variability in outcome and resource use in intensive care units. Intensive Care Med 33:1329-1336

47. Sexton JB, Berenholtz SM, Goeschel CA, Watson SR, Holzmueller CG, Thompson DA, Hyzy RC, Marsteller JA, Schumacher K, Pronovost PJ (2011) Assessing and improving safety climate in a large cohort of intensive care units. Crit Care Med 39:934-939
48. Azoulay E, Timsit JF, Sprung CL, Soares M, Rusinova K, Lafabrie A, Abizanda R, Svantesson M, Rubulotta F, Ricou B, Benoit D, Heyland D, Joynt G, Francais A, Azeivedo-Maia P, Owczuk R, Benbenishty J, de Vita M, Valentin A, Ksomos A, Cohen S, Kompan L, Ho K, Abroug F, Kaarlola A, Gerlach H, Kyprianou T, Michalsen A, Chevret S, Schlemmer B (2009) Prevalence and factors of intensive care unit conflicts: the Conflicus Study. Am J Respir Crit Care Med 180:853-860

49. [No authors listed] (1997) Fair allocation of intensive care unit resources. American Thoracic Society. Am J Respir Crit Care Med 156:1282-1301

50. Dawson S, Runk JA (2000) Right patient? Right bed? A question of appropriateness. AACN Clin Issues 11:375-385

51. Pirret AM (2002) Utilizing TISS to differentiate between intensive care and high-dependency patients and to identify nursing skill requirements. Intensive Crit Care Nurs 18:19-26

52. Iapichino G, Radrizzani D, Rossi C, Pezzi A, Anghileri A, Boffelli S, Giardino M, Mistraletti G, Bertolini G (2007) Proposal of a flexible structuralorganizing model for the intensive care units. Minerva Anestesiol 73:501-506

53. Wild C, Narath M (2005) Evaluating and planning ICUs: methods and approaches to differentiate between need and demand. Health Policy 71:289-301

54. Moreno R, Reis Miranda D (1998) Nursing staff in intensive care in Europe: the mismatch between planning and practice. Chest 113:752-758

55. Duke GJ, Green JV (2001) Outcome of critically ill patients undergoing interhospital transfer. Med J Aust 174:122-125

56. Wunsch H, Angus DC, Harrison DA, Collange O, Fowler R, Hoste EA, de Keizer NF, Kersten A, Linde-Zwirble WT, Sandiumenge A, Rowan KM (2008) Variation in critical care services across North America and western Europe. Crit Care Med 36(2787-2793):e2781-e2789

57. Hutchings A, Durand MA, Grieve R, Harrison D, Rowan K, Green J, Cairns J, Black N (2009) Evaluation of modernisation of adult critical care services in England: time series and cost effectiveness analysis. BMJ 339:b4353

58. Valentin A, Capuzzo M, Guidet B, Moreno R, Metnitz B, Bauer P, Metnitz $P$ (2009) Errors in administration of parenteral drugs in intensive care units: multinational prospective study. BMJ 338:b814 
59. Pizzi LT, Goldfarb NL, Nash DB (2001) Promoting a culture of safety. In: Shojania KG, Duncan BW, McDonald DM, et al. (eds) Making health care safer: a critical analysis of patient safety practices. Evidence report/technology assessment number 43. AHRQ, Washington DC

60. Najjar-Pellet J, Jonquet O, Jambou P, Fabry J (2008) Quality assessment in intensive care units: proposal for a scoring system in terms of structure and process. Intensive Care Med $34: 278-285$

61. Garland A (2005) Improving the ICU: part 1. Chest 127:2151-2164
62. Garland A (2005) Improving the ICU: part 2. Chest 127:2165-2179

63. Donchin Y, Seagull FJ (2002) The hostile environment of the intensive care unit. Curr Opin Crit Care 8:316-320

64. Bastos PG, Knaus WA, Zimmerman JE, Magalhaes A Jr, Sun X, Wagner DP (1996) The importance of technology for achieving superior outcomes from intensive care. Brazil APACHE III Study Group. Intensive Care Med 22:664-669
65. Hahnel J, Friesdorf W, Schwilk B, Marx T, Blessing S (1992) Can a clinician predict the technical equipment a patient will need during intensive care unit treatment? An approach to standardize and redesign the intensive care unit workstation. J Clin Monit 8:1-6

66. Quinio P, Baczynski S, Dy L, Ferrec G, Catineau J, de Tinteniac A (2003) Evaluation of a medical equipment checklist before intensive care room opening. Ann Fr Anesth Reanim 22:284-290 